The Egyptian Journal of Hospital Medicine (April, 2012) Vol., 47: 226- 237

\title{
Antibacterial Effectiveness Of Low Energy Diode Laser Irradiation On Management Of Periodontitis In Down Syndrome
}

\author{
Howida M. Sharaf *, Adel M. Elkhodary**, Ali E. Saafan***, Mostafa I. Mostafa ${ }^{*}$, \\ Sahar M.El Hadidy ${ }^{\circ}$ and Hanaa M. EIShenawy ${ }^{\circ}$
}

\author{
Department of Clinical Pathology, Ain Shams University Hospitals*, \\ Department of Orodental Biomaterials, Faculty of Dentistry, Cairo University** \\ Department of Dental Laser Application, National Institute for Laser Science***. \\ Department of Orodental Genetics, Human Genetics \& Genome Research Division, \\ National Research Center ${ }^{\circ}$
}

\begin{abstract}
Background: With the poor oral hygiene exhibited by patients with Down syndrome, the potential for a robust flora arises causing Periodontitis. Along with periodontal disease, the patient population has other medical conditions that limit treatment. This study was conducted to evaluate the antibacterial effectiveness of an 870-nm diode laser on periodontitis in patients with Down syndrome.

Subjects \& methods :Thirty five patients with Down syndrome suffering from periodontitis were included in this study and divided into two groups, Group I (25 patients) laser was applied to one half of the mouth and the other half was considered as a control \& Group II included (10 patients) basic periodontal treatment was applied to evaluate the systemic effect of laser. Quantification of A. actinomycetemconcomitans, P. Gingivalis and Capnocytophaga were carried out using real-time PCR technique at baseline and at 2 weeks, at 6 weeks and at 12 weeks post periodontal and laser treatment.

Results: A. Actinmycetcomitans and P. gingivalis were the most common organisms found in the studied patients and Capnocytophaga was the least common organisms. In group I the quantitative results of A. actinomycetemconcomitans, P. Gingivalis at 2 weeks were significantly lower in both sides of mouth than that of baseline level.After 6 week, it was still significantly lower than that of the baseline in the right side of the mouth, but at 12 weeks no significant difference was observed in both sides. In group II, quantitative results of A. actinomycetemconcomitans, P. Gingivalis at 2 weeks were also significantly lower than that of baseline but not at $6 \&$ at 12 weeks. As regards, Capnocytophaga there was no significant difference at baseline, at 2 weeks, at 6 weeks and at 12 weeks post periodontal and laser treatment in both groups I \& II.
\end{abstract}

Conclusion, scaling and root planning plus laser therapy was better than scaling and root planning alone in the chosen patients and this antibacterial effect continues to be significant up to 6 weeks after therapy.. Based upon the results of the study, it was found that Laser therapy could be used for the treatment of periodontitis as a complementary therapy not to replace mechanical intervention.

Key wards: Down syndrome, Periodontitis, A. Actinmycetcomitans and P. gingivalis

\section{Introduction}

Down syndrome, or trisomy 21 (T21), was first described by John Langdon Down in 1866. Down identified the phenotypic expression of patients with circulation and coordination problems as having Down syndrome.Generally, these patients now live to age 50 and some to age 60 . As life expectancy increases, medical and social costs raised more attention. Also, social changes have allowed for better quality of life. Dental practitioners are challenged by the high incidence of early onset of aggressive periodontal disease in T21; these patients have higher levels of periodontal pathogens and periodontitis-associated interproximal bone loss. The complex anatomy, physiology, immunology, and microbiology underscore the need for further investigations in specific areas related to their dental treatment (Alon Frydman and Hessam Nowzari, 2010)

There is an alteration in immune response that may contribute to the development of periodontal 
disease, which is more frequently seen among Down syndrome patients than in other mentally retarded or healthy patients. Approximately 35\% of adolescents with Down syndrome exhibited early signs of alveolar bone loss. Furthermore, a higher prevalence of periodontal pathogen Actinobacillus actinomycetemcomitans in subgingival plaque from Down syndrome patients compared to controls (Galley, 2005).

Periodontal disease is a group of inflammatory disorders, the patho-physiology of which is related to tooth accumulated microbial plaque and the host response to those accumulations. Kamma et al. (2006) stated that major forms of periodontal disease are considered to represent bacterial infections in which certain bacteria appear to play a significant role in inducing and maintaining the inflammatory process.

Some oral bacteria, including the periodontal pathogens and the cariogenic pathogens, are susceptible to killing by red light after their sensitization with toluidine blue O (TBO). Killing of Streptococcus sangius, as one of the most common species found in dental plaque, was achieved following exposure to $\mathrm{He}-\mathrm{Ne}$ light for 75 seconds, in the presence of toluidine blue $\mathrm{O}$ at a concentration of $2.5 \mu \mathrm{g} / \mathrm{mL}$ (Soukos et al., 1996).

Low-output diode laser today emits red and orange wavelengths, and are used for ophthalmology and dental applications. Researches are developing diode laser systems for other surgical applications. The advancement of this technology will continually threaten other laser systems because these units are more compact and cost-effective (Qadri etal., 2005).

Antibacterial activity of lasers depends on the radiation power, dose, wavelength, and the type of bacteria. High doses of laser radiation are known to possess an antimicrobial effect; however, they cause tissue destruction (Urneda et al., 2004). Low doses are either inactive or may stimulate the growth and reproduction of bacteria. The antibacterial activity of low power lasers may be achieved by their use in combination with photosensitizers, which under the influence of light energy initiate the formation of reactive oxygen, e.g. single oxygen or super oxide anions damaging bacterial cells (Gutknecht et al.,2004).

The purpose of this study was to evaluate the antibacterial effectiveness of an 870-nm diode laser on periodontitis in patients with Down syndrome.

\section{Subjects and Methods}

This study included thirty five patients previously diagnosed by both clinical and cytogenetic findings as having Down syndrome suffering from periodontitis. Their ages ranged between 12 -19 years selected from the outpatient clinic of the Orodental Genetic Department of the National Research Center, Cairo.

After having a written consent, the patients were divided into two groups:

- Group I: Included 25 patients in which laser was applied to one half of the mouth and the other half was considered as a control.

- Group II: Included 10 patients in which basic periodontal treatment was applied to avoid the systemic effect of low level laser therapy (LLLT) on the none laser side that may alter the results.

Diagnosis of periodontitis as evidenced by clinical examination with periodontal pocket depth more than $4 \mathrm{~mm}$. The participants have no ongoing general disease and had neither previous periodontal treatment during the last 6 months and antimicrobial drugs during the last 3 months nor received laser treatment before treatment befor, (Carranza, 2002).

Initially all participants received periodontal treatment including scaling and root planning (SRP) of all the mouth. Then the split mouth design was performed as the $1^{\text {st }}$ half (The right side of the mouth): was subjected to scaling and root planning (SRP) with the standard technique in combination to application of low level laser therapy. And the $2^{\text {nd }}$ half (The left side of the mouth): was subjected to scaling and root planning with the standard technique without application of low level laser therapy.

Before Laser application, the patients were systemically evaluated according to the dental modification of the Cornell Medical Index to standardize their systemic condition (Loe and Silness, 1963).

\section{Laser Treatment:}

Laser Treatment was applied in the first visit following baseline periodontal therapy and applied to the right half of the patient's mouth according to the split mouth design.A Soft Laser SL-202 (PETROLASER, Pr. Stachen, Saint-Petrsburg, 198097, Russia) was used for Laser therapy with an $870 \mathrm{~nm}$ wave length. It was used in a continuous contact modulated mode with $30 \mathrm{mw}$ power setting and $\mathrm{K} 30$ tip type that has $0.03 \mathrm{~cm}$. Irradiance surface area (supplied with the machine).

The power density of laser irradiation $=498 \mathrm{mw} / \mathrm{cm}^{2}$ (it depends upon laser output power (pin in mw) and 
the fiber tip type (tip losds coefficient), the energy density of laser irradiation $=10 \mathrm{~J} / \mathrm{cm}^{2}$. The tip end was directed to the pocket probing depth parallel to the long axis of root surface aiming at the diseased soft tissues lining of the pockets and moved all around the tooth. The tip moved from the apical point to the top of the pocket making overlapping horizontal and vertical movements maintaining slight contact with soft tissues at all times. Every laser application was performed for 40 seconds. This procedure was repeated three times with 20 minutes intervals after each application (Qadri et al., 2005 and Kamma et al., 2006).

\section{Microbiological evaluation:}

Subgingival plaque samples or buccal swabs were collected at baseline, at 2 weeks, at 6 weeks and at 12 weeks post periodontal and laser treatment. Quantification of A. actinomycetemconcomitans, P. Gingivalis and Capnocytophaga were carried out using real-time PCR technique according to Morillo et al. (2004).

- Isolation and Purification of Bacterial DNA using QIAamp DNA Mini kit Supplied by Qiagen (Germany).

- Real time PCR quantification method using 7300 real time PCR system (Applied biosystem USA, TaqMan). Primer and probe design and synthesis were done on basis of the published genomic sequence of Actinobacillus actinomycetumcomitans (Aa), Prophromonas Gingivalis (Pg) and Capnocytophaga canimorsus $(\mathrm{Cc})$ were obtained from the Gene Bank (U51862, DQ093272 and AF543295 respectively.)

Gene Specific primers and probes were obtained by means of the Primer Express Software (Applied Biosystems, Foster City, CA, USA.), and checked

Table 1: PCR Master Mix for each sample:

\begin{tabular}{|l|c|c|}
\hline Reaction Component & $\boldsymbol{\mu L} /$ Sample & $\begin{array}{c}\text { Final } \\
\text { Concentration }\end{array}$ \\
\hline TaqMan® Universal PCR Master Mix $(2 X)^{*}$ & $12.5 \mu \mathrm{L}$ & $1 \mathrm{x}$ \\
\hline Forward primer & $2.5 \mu \mathrm{L}$ & $900 \mathrm{nM}$ \\
\hline Reverse primer & $2.5 \mu \mathrm{L}$ & $900 \mathrm{nM}$ \\
\hline TaqMan® probe & $1.25 \mu \mathrm{L}$ & $250 \mathrm{nM}$ \\
\hline DNA sample & $3 \mu \mathrm{L}$ & \\
\hline Nuclease-free water & $3.25 \mu \mathrm{L}$ & \\
\hline Total & $\mathbf{2 5} \boldsymbol{\mu L}$ & \\
\hline
\end{tabular}

All reagents were supplied by Applied Biosystem, USA.

Table 2: Thermal Cycling profile

\begin{tabular}{|l|c|c|c|c|}
\hline \multirow{2}{*}{ PCR } & \multicolumn{2}{|c|}{ Initial Steps } & \multicolumn{2}{c|}{ PCR (Each of 40 cycles } \\
\cline { 2 - 5 } & AmpErase*UNG & AmpliTag Gold*DNA & Melt & Anneal / Extend \\
\hline
\end{tabular}


Antibacterial Effectiveness....

\begin{tabular}{|c|c|c|c|c|}
\hline \multirow{3}{*}{ Step } & Activation & Polymerase Activation & \multicolumn{2}{|c|}{} \\
\cline { 2 - 5 } & Hold & Hold & \multicolumn{2}{|c|}{ Cycle } \\
\cline { 2 - 5 } & $2 \min$ at $50^{\circ} \mathrm{C}$ & $10 \min$ at $95^{\circ} \mathrm{C}$ & $15 \mathrm{sec}$ at $95^{\circ} \mathrm{C}$ & 1 min at $60^{\circ} \mathrm{C}$ \\
\hline
\end{tabular}

\section{Quantification of Aa, Pg and Cc:}

Ten fold dilutions were prepared from pure $\mathrm{Aa}, \mathrm{Pg}$ and $\mathrm{Cc}$ in order to obtain different cell concentrations $\left(10^{1}-10^{6}\right)$.

\section{Data Analysis :}

The outcome variable used to evaluate the reproducibility of this assay was cycle threshold (CT). This is the cycle number at which the reaction begins to be exponential for a known number of DNA copies. The reaction at each DNA concentration was repeated fivefold. Means and standard deviations were obtained to calculate the coefficient of variation (CV) for each DNA concentration. A reliability analysis was carried out using intra-class correlation coefficients (ICCs) with a two-way random effects model (absolute agreement) (SPSS software v. 11.0).

\section{Statistical Analysis:}

Statistical Analysis was done using SPSS Program version 12. Descriptive statistics were done including mean, standard deviation and prevalence. Paired student's t-test was done to compare between the two halves of the mouth regarding the continuous variables. Chi-square test was done to compare between the two halves of the mouth regarding the categorical variables. One way analysis of variance was done to compare between the controls and the two halves of the mouth. P < 0.05 was considered significant.

\section{Results}

In group I: Ages of participants ranged between 1219 years with a mean of $14.5 \pm 3.5$ years. They were 19 males $(76 \%)$ and 6 females $(24 \%)$. The mean number of teeth was $22 \pm 2$ teeth. In group II: Their age ranged between 12-19 years with a mean age of $14 \pm 4.5$ years. They were 8 males $(80 \%)$ and 2 females (20\%). The mean number of teeth was $22 \pm$ 2 teeth.

In group I, it was found that there was no statistically significant difference between the right side (SRP + LAS), left side (SRP alone) and control subjects (SRP alone) regarding the mean score of plaque index, gingival index, pocket depth, degree of mobility and attachment level at the baseline periodontal examination $(\mathrm{P}>0.05)$.

Furthermore, the right side of the mouth in group I which received scaling and root planning plus laser therapy (SRP+LAS), at the different follow up periods, the plaque index, gingival index and mean level of attachment decreased significantly after 2 weeks and after 6 weeks $(\mathbf{P}<\mathbf{0 . 0 5})$, but after 12 weeks, the mean plaque index score was not significant from that of the baseline score $(\mathbf{P}>\mathbf{0 . 0 5})$. The mean pocket depth decreased significantly after 2 weeks, after 6 weeks and after 12 weeks $(\mathbf{P}<$ 0.05). The degree of mobility didn't change during all the follow up periods $(\mathbf{P}>\mathbf{0 . 0 5})$ (Figure1). While, the left side of the mouth at the different follow up periods, the plaque index, gingival index, pocket depth, level of attachment decreased significantly after 2 weeks $(\mathbf{P}<\mathbf{0 . 0 5})$, but after 6 weeks and after 12 weeks, there was not significant change from that of the baseline score $(\mathbf{P}>\mathbf{0 . 0 5})$. The degree of mobility didn't change during all the follow up periods ( $(\mathbf{>} \mathbf{0 . 0 5})$ (Figure2). 


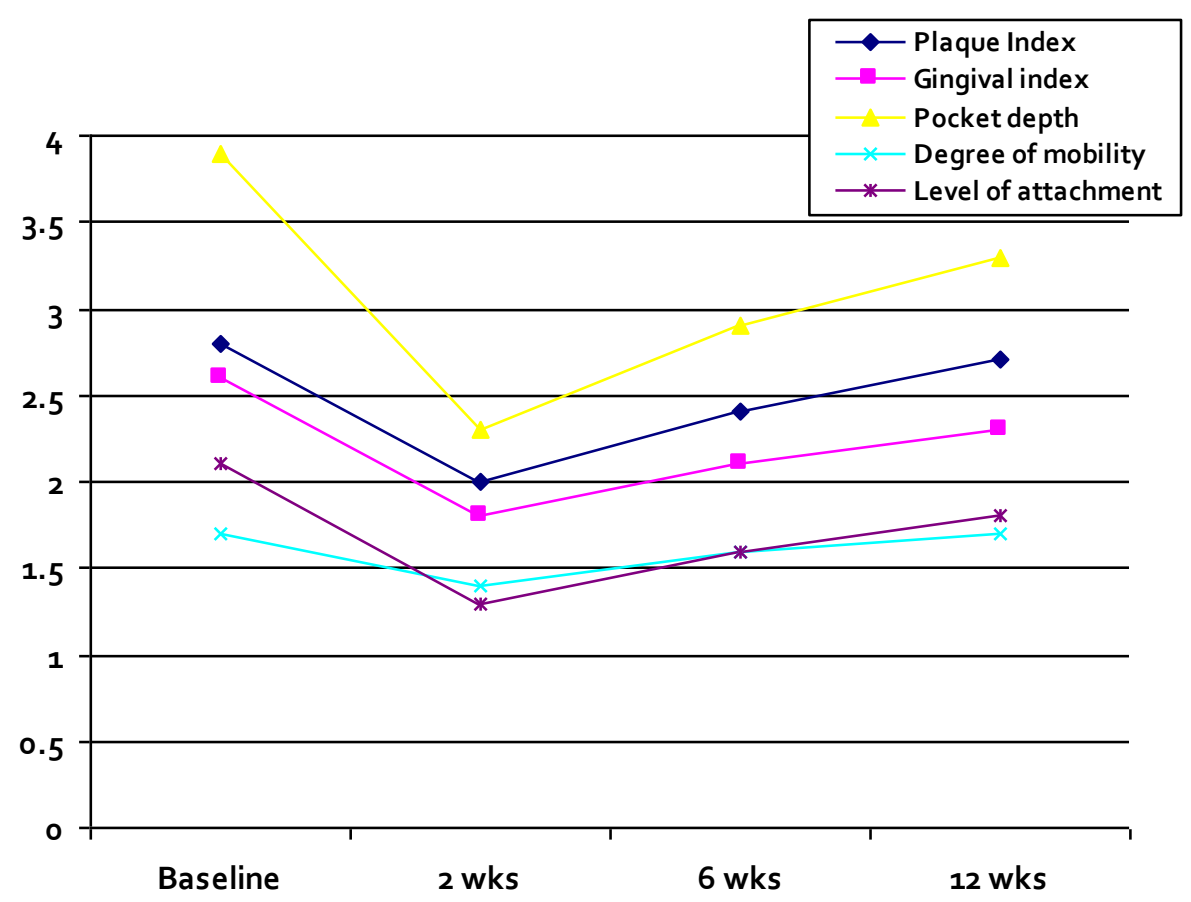

Figure (1): Periodontal examination of the right side of the mouth (SRP + LAS) at the different follow up periods

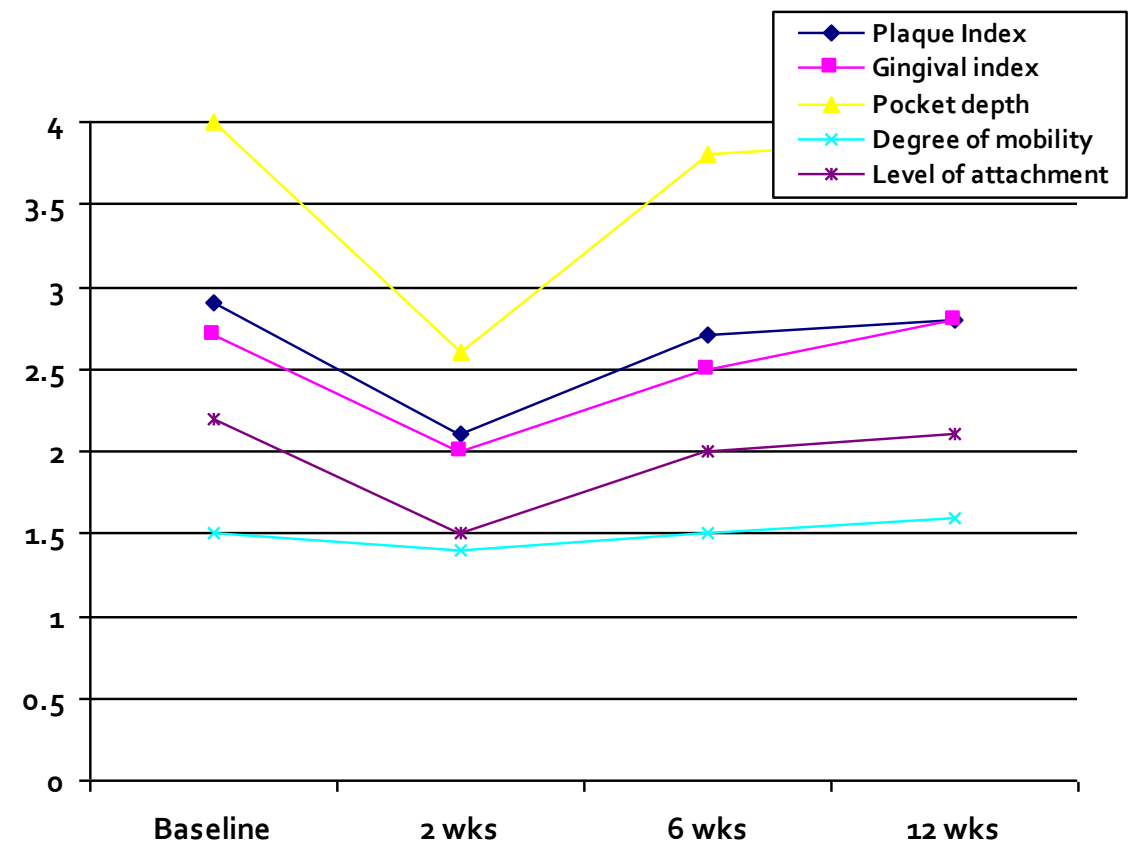

Figure (2): Periodontal examination of the left side of the mouth (SRP alone) at the different follow up periods.

In control group (10 patients), the plaque index, gingival index, pocket depth, level of attachment decreased significantly after 2 weeks $(\mathrm{P}<0.05)$, but after 6 weeks and after 12 weeks, there was no significant change from that of the baseline score $(\mathrm{P}>0.05)$. The degree of mobility didn't change during all the follow up periods $(\mathrm{P}>$ 0.05 )

A. Actinmycetcomitans and P. gingivalis were the most common organisms found in the studied patients and Capnocytophaga was the least common organisms. 
The quantitative results of A. Actinoycetemcomitans \& P. Gingivalis of the two sides of the mouth showed that after 2 weeks; the bacteria in both left and right sides of the mouth were significantly lower than that of the baseline $(P<0.001)$. After 6 weeks, the bacterial count of the left side was not significantly lower than that of the baseline $(\mathrm{P}>0.05)$; while in the right side of the mouth, the bacterial count was still significantly lower than of the baseline $(\mathrm{P}<0.05)$. After 12 weeks, the bacterial count of both left and right sides of the mouth was not significantly different from that of the baseline $(\mathrm{P}>0.05)$ (Table 3). Also, the quantitative results of $\mathrm{A}$.

Actinoycetemcomitans \& P. Gingivalis of the control group showed that after 2 weeks; the bacterial count were significantly lower than that of the baseline $(\mathrm{P}<0.001)$. After 6 weeks and after 12 weeks the bacterial count was not significantly lower than that of the baseline $(\mathrm{P}>0.05)$.

Table 3: Quantitative results of Actinobacillus actinomycetemconcomitans (A.a.) and Prophromonas gingivalis (P.g.) of the two sides of the mouth:

\begin{tabular}{|c|c|c|c|c|c|c|c|}
\hline & Baseline & \multicolumn{2}{|c|}{2 weeks } & \multicolumn{2}{|c|}{6 weeks } & \multicolumn{2}{|c|}{12 weeks } \\
\hline & & LS & $\mathbf{R S}$ & LS & RS & LS & RS \\
\hline A.a. & $3.11 \pm 0.40$ & $2.23 \pm 0.31 *$ & $1.77 \pm 0.37 *$ & $\begin{array}{l}3.08 \pm \\
0.40^{* * *}\end{array}$ & $2.36 \pm 0.40 *$ & $3.13 \pm 0.40 * *$ & $3.09 \pm 0.40^{* *}$ \\
\hline P.g. & $2.51 \pm 0.40$ & $2.00 \pm 0.35^{*}$ & $1.48 \pm 0.30^{*}$ & $2.23 \pm .37 * *$ & $1.89 \pm 0.25^{*}$ & $2.53 \pm 0.41 * *$ & $2.49 \pm 0.41 * *$ \\
\hline
\end{tabular}

$* P<0.05$ (significant difference) in comparison to baseline value.

$* * \mathbf{P}>\mathbf{0 . 0 5}$ (non significant difference) in comparison to baseline value.

The quantitative results of Capnocytophaga in the two sides of the mouth showed that there was no significant difference between the baseline bacterial count and after 2, 6 and 12 weeks in both sides of the mouth $(\mathrm{P}>0.05)$ (Figure 3 ). Also, the quantitative results of Capnocytophaga in the controls showed that there was no significant difference between the baseline bacterial count and after 2, 6 and 12 weeks in the controls $(\mathrm{P}>0.05)$.

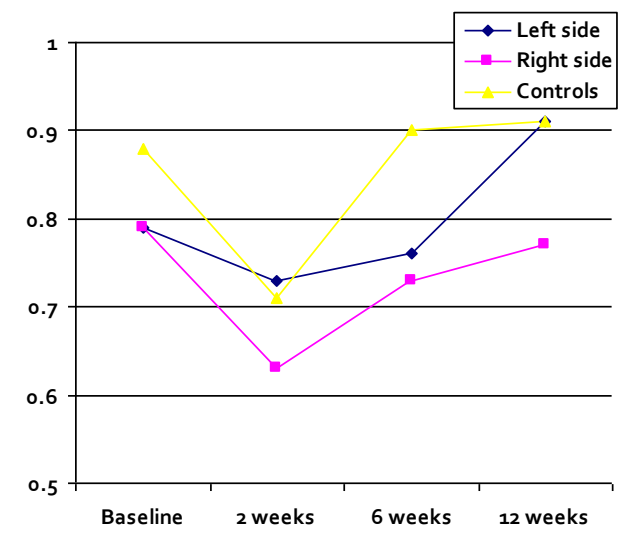

Figure (3): Quantitative results of Capnocytophaga of the two sides of the mouth

The comparison between the left side of the mouth and controls revealed no significant difference regarding the quantitative analysis of A. Actinomycetcomitans. P. Gingivalis and Capnocytophaga at the different follow up periods $(\mathrm{P}>0.05)$ (Table 4). 
Table 4: Quantitative results of the 3 organisms of the left side of the mouth and controls at the different follow up periods

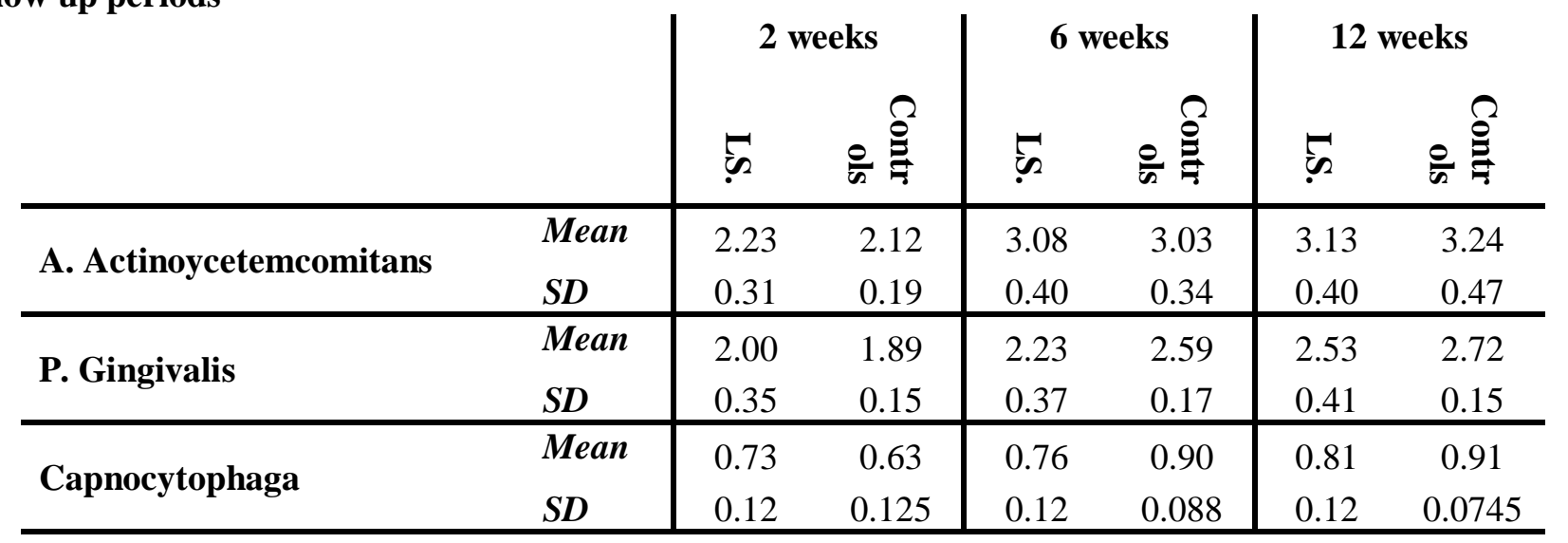

\section{Discussion}

In the current study, we selected patients with Down syndrome who have periodontitis because those patients need more dental care, as caries, and preventive dentistry approaches should be considered in management of the oral health needs of patients with Down syndrome. The following items are the rationale for studying patients with Down syndrome. Early onset of periodontal disease often begins with the primary dentition. Rapidly progressing periodontal disease leads to early tooth loss (Charles, 2006).

Children with Down syndrome have a different leukocyte response together with more extensive gingival inflammation than do children without Down syndrome (Reuland-Bosma and VanDijk, 1986). Progression of periodontal disease is marked by occasional acute symptoms (infection, inflammation, pain) followed by chronic progression of disease (Dixon and Stewart, 1999). Factors that lead to a higher susceptibility of periodontal disease in patients with Down syndrome include atypical patterns of T-cell immunodeficiency together with functional defects of polymorphonuclear leukocytes and monocytes (Sanz and Quirynen ,2005).

The individual has an inadequate reaction to bacterial attack, altered make up of connective tissue, and an antigenic stimulus overloading an immature immune system. This is seen more frequently in people with Down syndrome living in care facilities compared with those living at home (Kamma et al., 2006). Although 40 to $50 \%$ of babies with Down syndrome are born with some type of cardiac abnormality, approximately $50 \%$ of adults with Down syndrome have Mitral Valve Prolapse (MVP) which predisposes them to subacute and acute bacterial endocarditis (Barnett et al., 1988 and Limbrock et al., 1991).

Oral hygiene regimens and the motivation of the dental team influence the oral health of all individuals. Systemic problems also require appropriate precautions and therapy for patients with Down syndrome. Preventive dental health practices in children with Down syndrome are decreased when less help is given during tooth brushing. Decreased musculoskeletal development suggests a need to ensure attention to oral hygiene practices with assistance when necessary. Similarly, children with Down syndrome are less likely to be taking fluoride supplements and are older when making their first dental visit (Randell et al., 1992).

The selected age was of 12-19 years because Shapira and Stabholz, (1996) mentioned that the early teenage years are the best time for patients with Down syndrome to understand and cooperate effectively in preventive dental programs. This study was conducted to evaluate the antibacterial effectiveness of an 870-nm diode laser on periodontitis in patients with Down syndrome. Moritz et al. (1998) reported considerable bacterial elimination from periodontal pockets using irradiation with an 810-nm diode laser with $2.5 \mathrm{~W}$ power settings in pulsed mode $(50 \mathrm{~Hz}$, pulse duration $10 \mathrm{~ms}$ ) following scaling as compared to scaling alone. The selection of this low level laser therapy in our study is based on that it is not always possible to select the optimal laser and treatment parameters for laser therapy because of the lack of adequate studies. The parameters used in this study seem to have been within the "therapeutic window" of dosage but not necessarily optimal. Many studies have failed to find this window, especially in studies 
performed in the 1980s and early 1990s (Dederich and Bushick, 2004).

In this study, 10 control patients with Down syndrome in which SRP was alone without Laser application to avoid the systemic effects of Laser as the systemic effect of therapeutic laser light has been described by many researchers, such as Airaksinen et al. (1998) and Frentzen etal.(2002). Essentially, a systemic effect is one such that treatment of a given condition at one site will also tend to affect a similar condition elsewhere. It is therefore important to observe caution in interpreting the result of studies in which parts of the test person's/animal's body has been treated by laser and another part of the same body has been used as a control, especially in small animal studies (Airaksinen et al., 1998).

Furthermore, In group I it was found that the right side of the mouth which received scaling and root planning plus laser therapy (SRP+LAS), at the different follow up periods, the plaque index, gingival index and mean level of attachment decreased significantly after 2 weeks and 6 weeks with no change after 12 weeks, the mean plaque index score was not significant from that of the baseline score. The pocket depth decreased significantly after 2 weeks, 6 weeks and 12 weeks. The degree of mobility didn't change during all the follow up periods. These results denote that the impact of laser therapy in combination to scaling and root planning extended till the 6th week of therapy but the effect became insignificant after 12 weeks of therapy. This was in agreement with Coluzzi (2002); On the other hand, Qadri et al. (2005) found that the results differed in that the effect of laser therapy extended to the 12th week. This difference could be attributed to the higher energy power of the used laser system in their work (980 $\mathrm{nm}$ diode laser) while that applied in the current study was an $870 \mathrm{~nm}$ laser. Also the difference in the results may be due to the patients included in the current work had Down syndrome and all of them had orodental abnormalities that may have affected the results and deteriorated the periodontal condition.

As regards, the left side of the mouth where scaling and root planning (SRP) was done, at the different follow up periods, the plaque index, Gingival index, pocket depth, level of attachment decreased significantly after 2 weeks, but after 6 weeks and 12 weeks, there was no significant change from that of the baseline score. The degree of mobility didn't change during all the follow up periods $(\mathrm{P}>0.05)$. These results indicate the important role of scaling and root planning for the treatment of periodontitis as it is one of the most commonly utilized procedures for the treatment of periodontal diseases and has been used as the gold-standard treatment for many researchers. Mechanical treatment alone has been shown to be clinically and microbially effective. The clinical benefits are derived from the removal of subgingival plaque and disruption of subgingival biofilm leading to a decrease of bacterial counts (Qadri et al., 2005)

However, there was no significant difference between left side and right side of the mouth after 6 weeks regarding the plaque index (as this index depends mainly on patient's behavior) and degree of mobility. There was significant difference between left side and right side of the mouth after 6 weeks regarding gingival index, pocket depth and level of attachment. There was no significant difference between the controls and right side of the mouth of the studied group regarding the plaque index and degree of mobility. Furthermore, there was significant difference regarding gingival index, pocket depth and level of attachment. Also there was no significant difference between left side and right side of the mouth after 12 weeks regarding the plaque index and degree of mobility. There was significant difference between left side and right side of the mouth after 12 weeks regarding gingival index, pocket depth and level of attachment. Comparison between the controls and right side of the mouth of the studied group showed that there was no significant difference regarding the plaque index and degree of mobility. There was significant difference regarding gingival index, pocket depth and level of attachment.

Some of the effects of laser therapy on the periodontium may be because of an increase in the microcirculation in the irradiated area (Schaffer $\boldsymbol{e t}$ al., 2000). In a study of gingival microcirculation using healthy volunteers with experimental gingivitis, no effects were seen (Aoki et al.,2000), but other authors have shown that low-level laser affected the microcirculation in mildly inflamed gingiva, but not in uninflamed or severely inflamed gingiva (Kozlov et al., 1984). On the other hand, when the microcirculation in the masseter muscle was studied (Tullberg $\boldsymbol{e t}$ al., 2003), no increase in microcirculation occurred in tender areas, but a significant increase was noted in similar locations in healthy volunteers.

In this study, A. Actinmycetcomitans and P. gingivalis were the most common organisms found in the studied patients, and Capnocytophaga were the least common organisms.In Down syndrome, Porphyromonas gingivalis, Actinobacillus 
actinomycetemcomitans and capnocytophaga were detected with greater frequency. Porphyromonas gingivalis was widely distributed, increasing the severity of gingivitis in the group older than 5 years (Amano et al., 2001). Patients with Down syndrome have seven times the frequency of Actinobacillus actinomycetemcomitans and capnocytophaga than a non-Down syndrome control (Barr-Agholme et al., 1992). The relationship between gingivitis and the host response to oral microorganisms in Down syndrome by age shows different microbiological colonization for children younger than age 5 compared with associated gingivitis at puberty. Only A.actinomycetemcomitans colonization is associated in both groups (Contreras et al., 2000).

In the current study real time PCR was used instead of the traditional PCR. The limitations of the traditional PCR as endpoint detection is very time consuming \& agarose gel resolution is very poor, about 10 fold change. Real-Time PCR can detect as little as a two-fold change (Applied Biosystems, 2005).

In the present study, SRP alone was capable of appreciably decreasing the bacterial species tested, namely, P. gengivalis, A. actinomycetmconcomitans and capnocytophagna till the 6th week of therapy. These data confirm the favorable effects of SRP in decreasing the levels of these micro-organisms that has previously been reported in the studies of Darby et al. (2001) and Urneda et al. (2004). As shown in the present study, SRP+LAS was the most effective treatment modality, keeping the levels of all bacterial species at low level up to 6 weeks after therapy. The most favorable bacterial reduction was achieved 2 weeks post-therapy for all the bacterial species tested, although all species were still significantly reduced at 6 weeks when compared to pretreatment levels. This favorable effect might be due to the ability of laser irradiation to eliminate bacteria in the dentine tubules where they can act as a "reservoir" for recolonization and re-infection of the pocket (Gutknecht et al., 1997 and Gutknecht et al., 2004).

While SRP is the most commonly used periodontal therapy for the cause-related phase of treatment, there are limitations, including the inability to adequately instrument deep periodontal pockets and furcations as well as remove microorganisms within the tissues lining the periodontal pocket. Darby et al. (2001) have shown that scaling and root planning resulted in clinical improvement and significant reduction in the levels of $\mathrm{P}$. intermedia, $\mathrm{T}$. forsythia and T. denticola. Renvert et al. (1998) demonstrated similar results. However, A. actinomycetemcomitans still remained in a high proportion of sites after therapy, probably due to its ability to invade periodontal tissues. It is known that periodontal pathogens are capable of invading periodontal tissues. A. actinomycetemcomitans was found in the connective tissue of active as compared to nonactive sites (Saglie et al., 1988). In addition, P. gingivalis can adhere and enter oral epithelial cells (Sandros et al., 1994). Our results indicated that SRP alone was not able to eliminate A. actionmycetem-comitans, while laser-assisted curettage succeeded in eliminating this bacterium after the combined therapy. Laser-assisted treatment had an excellent effect on the-counts of T. forsythia, another periodontal pathogen which, according to clinical studies, is resistant to elimination by scaling and root planning (Karnma et al., 1999 and Takarnatsu et al., 1999).

Collectively, laser-assisted treatment when combined with subgingival debridement showed a substantial clinical improvement due to the favorable alterations detected in the subgingival microflora, thereby indicating that it is effective in the cause-related treatment of periodontitis where anaerobic bacteria are predominant therefore, this adjunctive therapy should not replace mechanical instrumentation but rather complement it (Qadri et al., 2005). As the 1989 and 1996 reviews in "World Workshops on Periodontology" Waerhaug (2004) indicated that there is controversy about the necessity for gingival curettage in the mechanical treatment of periodontitis. However, the presence of invading bacteria in deeper parts of dentinal tubules suggests that a purely mechanical therapy of SRP is unable to reach and eliminate these bacteria, especially in aggressive cases of periodontitis. Moreover, such bacterial invasion of root structure may represent a reservoir of periodontopathic bacteria for decolonization and re-infection (Aoki $\boldsymbol{e t}$ al., 2000). There are studies indicating that diode laser irradiation can destroy bacteria in the dentinal tubules and can penetrate deeper than chemicals (Gutknecht et al., 2001 and Kreis et al., 2003)

\section{Conclusion :}

A. Actinmycetcomitans and P. gingivalis were the most common organisms found in the studied patients 

and Capnocytophaga were the least common organisms. Scaling and root planning were effective in improving clinical and microbiological parameters in patients with Down syndrome and this effect continued for two weeks after therapy. While, Scaling and root planning plus laser therapy were better than scaling and root planning alone in the chosen patients and this antibacterial effect continues to be significant up to 6 weeks after therapy.. Based upon the results of the study, it was found that Laser therapy could be used for the treatment of periodontitis as a complementary therapy not to replace mechanical intervention.

\section{References}

Airaksinen O, et al (1998). Effects of laser irradiation at the treated and non-treated trigger points. Proc. 4th Intern Symposium. Acupunc \& Electrother Res; 13 (4): 238-239.

Alon Frydman, DDS, and Hessam Nowzari (2010). Down Syndrome-Associated Periodontitis: A Critical Review of the Literature Compendium of Continuing Education in Dentistry. Volume 31, Issue 8.

Amano A, Kishima T, Akiyayama S, Nakagawa I, Hamada $S$ and Morisaki L (2001). Relationship of periodontopathic bacteria with Early-Onset periodontitis in Down's syndrome. J Periodontol; 72: 368-373.

Aoki A, Miyuki Sasaki K, Watanabe $H$ and Ishlkawa I (2000). Lasers in non- surgical periodontal therapy. Periodontol; 3: 59-97.

Applied Biosystems (2005). Real-Time PCR vs. Traditional PCR. Roche Molecular Systems inc. P: 3-6.

Barnett ML, Friedman D, Kastner T and Morristown NJ (1988). The prevalence of mitral valve prolapse in patients with Down syndrome: implications for dental management. Oral Surg Oral Med Oral Pathol; 66: 4457.

Barr-Agholme M, Dahllöf G, Linder L and Modeer T (1992). Actinobacillus actinomycetemcomitans, Capnocytophaga and Porphyromonas gingivalis in subgingival plaque of adolescents with Down syndrome. Oral Microbiology and Immunology; 7: 244-8.

Charles, $M$ (2006). Lasers in periodontics: a review of the literature. J Periodontol ;77 (4):545-64

Carranza, FA (2002). Clinical diagnosis. In: Carranza's Clinical Periodontology. Chapter 30, pp. 445-447. WB Saunders Company, Toronto.

Coluzzi, DJ (2002). Lasers and soft tissue curettage: an update. Cornpend Contin Edu Dent; 23: 1104-1111.

Contreras A, Rusitanonta T, Chen C, Wagner WG, Michalowicz BS and Slots J (2000). Frequency of 530bp deletion in Actinobacillus actinomycetemcomitans leukotoxin promoter region. Oral Microbiology and Immunology; 15: 338-340.

Darby IB, Mponey J and Kinane DF (2001). Changes in subgingival microftors and humoral Immune response following periodontal therapy. J Clin Periodontol; 28: 706-9.

Dederich D and Bushick RD (2004). Lasers in dentistry: Separating science from hype. J Am Dent Assoc; 135: 204-208.

Dixon GH and Stewart RE (1999). Genetic aspects of anomalous tooth development. Oral Facial Genetics. Stewart RE, Prescott GF, eds. Mosby, St. Louis, pp12450.

Frentzen M, Braun A and Aniol D (2002). Er: YAG laser scaling of diseased root surfaces. J Periodontol; 73: 524-530.

Galley $R$ (2005). Medical management of the adult patient with Down syndrome. JAAPA; 18(4):45-52.

Gutknecht N, Fischer J, Conrads G and Lam pert $F$ (1997). Bactericidal effect of the Nd: YAG lasers in laser supported curettage. SPIE Proceedings of Lasers in Dentistry; 2973: 221-226.

Gutknecht N, Franzen R, Schippers $M$ and Lam pert F (2004). Bactericidal effect of a 980-nrn diode laser in the root canal wall dentin of bovine teeth. J Clin Laser Med Surg; 22: 9-13.

Gutknecht N, Zimmermann R and Lampert F (2001). Lasers in Periodontology: State of the art. J Oral Laser Applic; 1: 169-179.

Kamma JJ, Vasdekis VGS and Romanos GE (2006). Short-term effect of Diode Laser $(980 \mathrm{~nm})$ treatment on aggressive periodontitis. Evaluation of clinical and microbiological parameters. Journal of Oral Laser Applications; 6: 111-121.

Karnma JJ, Nakou M and Baehni PC (1999). Clinical and microbiological characteristics of smokers with early onset periodontitis. J Perio Fles; 34: 25-33.

Kozlov VI, Krechina E and Terman OA (1984). Lasers in diagnostics and treatment of microcirculation disorders under parodontitis. Proceedings of SPIE 1984, 253-264, Advanced Laser Dentistry; Altshuler GB, Blankenau RJ, Wigdor HA, Eds.

Kreis er M, Kohnen W, Beck M, Al Haj H, Chris toffers AB, Gotz H, Duschner $H$, Iansen $B$ and D'Hoedt B (2003). Efficacy of $\mathrm{NaOCI} / \mathrm{hhQz}$ irrigation and GaAIAs laser in decontamination of root canals in vitro. Lasers Surg Med; 32: 189-196.

Limbrock C, Fisher-Brandies H and Avalle C (1991). Castillo-moralès orofacial therapy: treatment of 67 children with Down syndrome. Developmental Medicine and Child Neurology; 33: 296-303.

Loe $H$ and Silness $J$ (1963). Periodontal disease in pregnancy. I. Prevalence and severity. Acta Odontol Scand; 21: 533-51.

Morillo JM, Lau L, Sanz M, Herrera D, Martin C and Silva A (2004). Quantitative real-time polymerase chain reaction based on single copy gene sequence for detection of parodontal pathogens. J Clin Periodontol; 31: 10541060.

Morinushi T, et al (1995). The relationship between dental caries in the primary dentition and anti S. Mutans 
serum antibodies in children with Down's syndrome. Journal of Clinical Pediatric Dentistry; 19: 279-83.

Qadri T, Miranda L, Tuner J and Gustafsson A (2005). The short-term effects of low-level lasers as adjunct therapy in the treatment of periodontal inflammation. J Clin Periodontol; 32: 714-719.

Randell DM, Harth S and Scow WK (1992). Preventive dental health practices of non-institutionalized Down syndrome children: a controlled study. J Clin Pediatr Dent; 11(6): 225-9.

Renvert S, Wikstrom M, Dahlen G, Slots J and Egelberg J (1998). Effect of root debridement on the elimination of Actinobacillus actinomy-cetemcomitans and Bacteroides gingivalis from periodontal pockets. $J$ Clin Periodontol; 17: 345-50.

Reuland-Bosma W and van Dijk J (1986). Periodontal disease in Down's syndrome: a review. $J$ Clin Periodontol; 13: 64-73.

Saglie FR, Marfany A and Camargo P (1988). Intragingival occurrence of Actinobacillus actinornyceterncornitans and Bacteroides gingivalis in active destructive periodontal lesions. J Periodont; 59: 259-65.

Sandros J, Papapanou PN, Nannreark LJ and Dahlen G (1994). Porphyromonas gingivalis invades human pocket epithelium in vitro. J Perio Res; 29: 62-9,

Sanz $M$ and Quirynen $M$ (2005). Advances in the aetiology of periodontitis. Group A consensus report of the $5^{\text {th }}$ European Workshop in Periodontology. Journal of Clinical Periodontology; 32: 54-56.

Schaffer M, Bonel H, Sroka R, Schaffer PM, Busch M, Reiser $M$ and Duhmke E (2000). Effects of $780 \mathrm{~nm}$ diode laser irradiation on blood microcirculation: Preliminary findings on time-dependent Tl-weighted contrast-enhanced magnetic resonance imaging (MRI). Journal of Photochemistry and Photobiology; 54, 55-60.

Shapira J and Stabholz A (1996). A comprehensive 30month preventive dental health program in a preadolescent population with Down's syndrome: a longitudinal study. Spec Care Dent; 16(1): 33-7.

Soukos NS, Wilson M, Burns $T$ and Speight PM (1996). Photodynamic effects of Toluidine blue on Human oral Keratinocytes and fibroblasts and Streptococcus sanguis evaluated in vitro. J Lasers Surg Med; 18: 253-259.

Takarnatsu N, Yano $K$, He T, LJrneda $M$ and Ishikawa I (1999). Effect of initial periodontal therapy on the frequency of detecting Bacteroides forsythus, Porphyrornonas gingivalis, and Actinobacillus actinomycetemcomitans. J Periodontol; 70: 5 74-80.

Tullberg M, Alstergren PJ and Ernberg MM (2003). Effects of low-power laser exposure on masseter muscle pain and microcir-culation. Pain; 105, 89-96.

Urneda M, Take uc hi Y, Noguchi K, HuangY, Koshy G and Ishikawa L (2004). Effects of nonsurgical periodontal therapy on the rnicrobiota. Periodontoiogy; 36: 98-120.

Waerhaug J. (2004). Healing of the dento-epithelial junction following subgingival plaque control, I. As observed in human biopsy material. Periodontol; 49: 1-8. 


\section{فاعلية الصمام الثنائى المنخفض الطاقة لأشعة الليزر كمضاد للبكتريا فى علاج التهاب اللثة في متلازمة داون

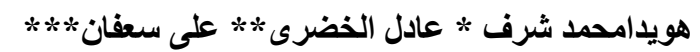

مع ضعف مستوى نظافة وصحة الفم فى مرضى متلازمة داون، واحتمال نمو قوي للوسط البكتيرى مما يسبب التهاب اللتة .فان إنمان

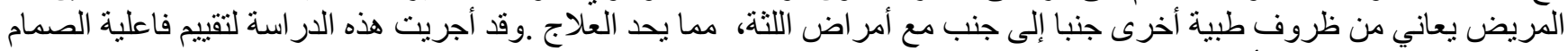

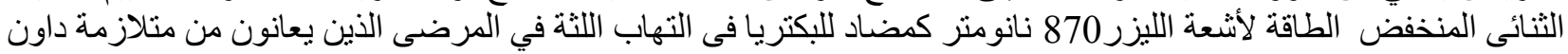

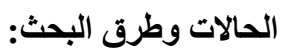

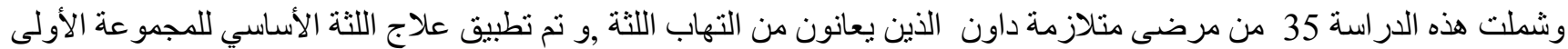

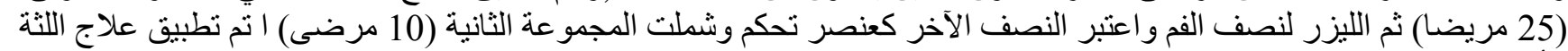

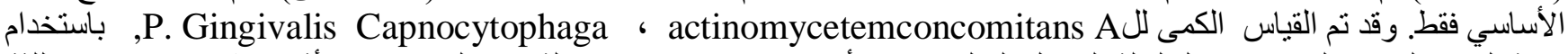
تقنية الوقت الحقيقى للاستنساخ لسلسلة التفاعل المبلمر في الأساس، و عند الاسبوع الثانى ، السادس و الأثنى عشر مابعد علاج اللثة والليزر

النتائتج:

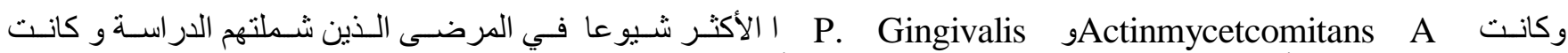
P. Gingivalis الأقل ـ و كانت النتائج الكمية في المجموعة الأولى لل. Capnocytophaga

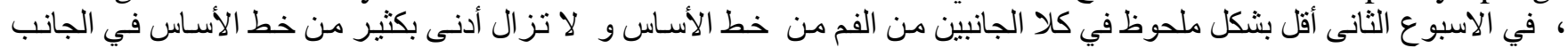

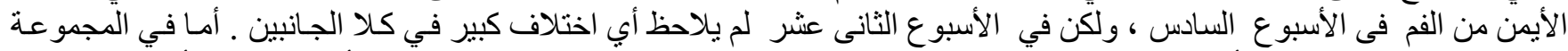

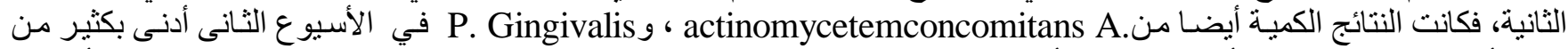

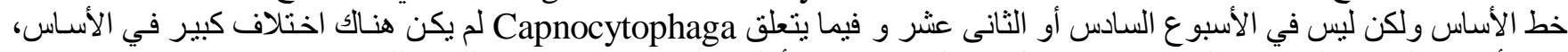
في الأسبوع الثانى و السادس و الثنانى عشر في كل من المجمو عتين الأولى والثانية مابعد علاج اللثنة والليزر.

الاستتناج:

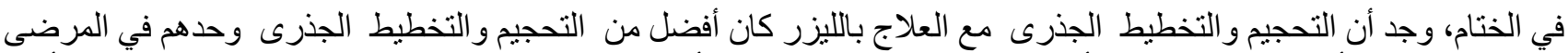

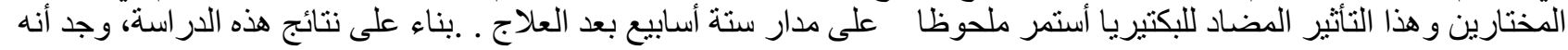

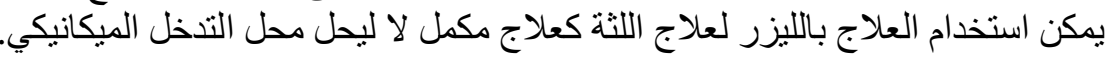

